\title{
Características clínicas y epidemiológicas de la infección por virus parainfluenza en niños hospitalizados
}

\author{
Luis E. Vega-Briceño, Dahiana Pulgar B., Marcela Potin S., Marcela Ferres G. e Ignacio Sánchez D.
}

\section{Clinical and epidemiological manifestations of parainfluenza infection in hospitalized children}

Background: Human parainfluenza viruses (hPIV) are a common cause of respiratory illness of children but published data on clinical characteristics of hPIV infection in South America is scarce. Objective: To review the clinical presentation and epidemiological features of hPIV in a series of hospitalized children in Chile. Patients and Methods: Retrospective review of clinical charts from all pediatric admissions with a diagnosis of respiratory disease (between January 2001 to December 2004) at the Catholic University Hospital, Santiago, Chile. Nasopharyngeal secretions were tested for hPIV in children admitted with suspected respiratory viral infections. Results: A total of 3,043 respiratory admissions were recorded during the study period; 64 children $(2.1 \%)$ were hPIV positive. Average age was 13 months (range: $1 \mathrm{~m}$ to $12 \mathrm{y}$ ) and $77 \%$ were younger than 2 years. HPIV-2 was the most common type identified (47\%). A seasonal trend was noted for serotypes hPIV-2 and 3. Acute wheezing (40\%) and pneumonia (30\%) were the most common clinical diagnosis in hPIV positive children and $17 \%$ hPIV positive children (44\% for hPIV-1) were associated with laryngitis. All hPIV positive bronchiolitis were due to serotypes hPIV-2 and 3. Conclusion: hPIV can cause respiratory disease requiring hospitalization; serotypes hPIV-2 and 3 displayed a seasonal trend. Although hPIV is an uncommon cause of severe respiratory infecion requiring hospitalization in children, it should be considered in the differential diagnosis of laryngitis, bronchiolitis and pneumonia, especially in younger children.

Key words: parainfluenza virus, children, hospitalized, epidemiology.

Palabras claves: virus parainfluenza, niños, hospitalizados, epidemiología.

\section{Introducción}

$\mathrm{L}$ os virus parainfluenza del ser humano (VPIh) son agentes importantes de infección del tracto respiratorio alto y bajo en niños y adultos ${ }^{1-4}$. Luego de su identificación en 1959, han sido establecidos como causa frecuente de enfermedad respiratoria en niños bajo dos años de edad, manifestándose como síndromes respiratorios altos leves (caracterizados por coriza, tos y fiebre), o cuadros de mayor gravedad como croup, bronquiolitis, traqueobronquitis y neumonía $^{2,5}$. Se reconoce que en sujetos con condiciones crónicas de base, como inmunocomprometidos o posttrasplantes, las infecciones por VPIh pueden ser graves $\mathrm{y}$ eventualmente mortales ${ }^{1,6}$.

Los VPIh son virus ARN de hebra simple, polaridad negativa, que pertenecen a la familia Paramixoviridae al igual que el virus respiratorio sincicial (VRS) y el metapneumovirus ${ }^{7}$. Contienen aproximadamente 15.000 nucleótidos y, en la actualidad, se han descrito cinco tipos de VPIh en la literatura científica, constituyendo los serotipos 1, 2 y 3 los más importantes desde el punto de vista médico ${ }^{7-9}$. Las manifestaciones clínicas dependen específicamente del serotipo de VPIh; sin embargo, también es importante la edad del paciente, el estado inmune y el momento epidemiológico del $\mathrm{año} 0^{2,7,10,11}$.

Los serotipos 1 y 2 se presentan con más frecuencia en verano y primavera en el hemisferio norte, infectando preferentemente a niños pre-escolares, a diferencia del serotipo 3 que infecta a pacientes de todas las edades, sin preferencias ${ }^{2,5}$. La desnutrición, hacinamiento, déficit de vitamina $\mathrm{A}$, falta de lactancia materna y exposición a humo de tabaco, son factores que favorecen la infección ${ }^{12,13}$. Muchos reportes describen el perfil epidemiológico de diversos virus en nuestro medio $^{14-21}$, principalmente $\operatorname{VRS}^{19,20}$, FLU $^{17,20,21}$ y ADV ${ }^{19}$, así como el impacto de la contaminación y el frío en relación con su circulación ${ }^{20}$; lamentablemente, existe
Pontificia Universidad Católica de Chile, Santiago, Chile

Departamento de Pediatría (LV-B, MPS, ISD)

Centro de Investigaciones

Médicas (MFG)

Esccuela de Medicina (DPB)

Recibido: 25 abril 2007

Aceptado: 27 julio 2007

Correspondencia a:

Luis E. Vega-Briceño

levega@puc.cl 
poca información publicada en Sudamérica que describa el perfil clínico-epidemiológico específico de VPIh en niños ${ }^{12,18}$; la mayoría de las publicaciones provienen del hemisferio norte o del Asia ${ }^{22-24}$.

El objetivo de este trabajo es describir el perfil clínico y epidemiológico específico de los pacientes hospitalizados por infección respiratoria por VPIh, en el Servicio de Pediatría del Hospital Clínico de la Pontificia Universidad Católica (HCPUC) durante el período enero de 2001 a diciembre de 2004.

\section{Pacientes y Métodos}

Se identificaron todas las hospitalizaciones por alguna condición respiratoria asociada a infección por VPIh en el Servicio de Pediatría del HCPUC, durante un período de 48 meses. Para este estudio, se incluyeron sólo aquellos niños con confirmación virológica efectuada mediante técnicas de IFD en muestras de secreción nasofaringea obtenidas con técnica de hisopado. Se consignaron las condiciones crónicas de base, síntomas y signos respiratorios al ingreso, evolución clínica, así como las complicaciones. Se registraron los exámenes de laboratorio solicitados, las razones de cada solicitud y el cambio en el tratamiento, luego de conocido el resultado. Para la técnica de detección de antígenos de VPIh se utilizaron anticuerpos monoclonales para VPIh serotipo 1, 2 y 3 (PathoDx, DPC, Los Angeles, CA 90045), los que se agregaron sobre las células fijadas con acetona. El diagnóstico de positividad correspondió a la visualización de, al menos, una célula con gránulos fluorescentes verde manzana de ubicación citoplasmática. Todas las muestras fueron también evaluadas para VRS, influenza A, B y adenovirus.

Definiciones. Probable neumonía bacteriana: pacientes con fiebre y crepitaciones pulmonares, que tuvieron alteración en el hemograma (leucocitosis $\left.>15.000 / \mathrm{mm}^{3}\right)$ asociada a PCR elevada $(>2$ veces el valor normal) o un ascenso ( $>2$ veces) respecto del valor de ingreso. Hipoxemia: saturación arterial de oxígeno menor o igual $92 \%$. Condición crónica de base: presencia de prematurez, enfermedad neurológica o muscular, genopatía, bronquiolitis obliterante, daño pulmonar crónico o cardiopatía. Sibilancias asociadas a virus: cuadro respiratorio bajo gatillado por una infección viral con presencia de sibilancias (incluye asma, bronquiolitis, bronquitis, traqueobronquitis). Sibilancias recurrentes: presencia de $\geq 3$ episodios de sibilancias confirmadas por médico. Niño sano: aquel sin ninguna de las condiciones antes mencionadas. Complicación: deterioro en la condición clínica, aso- ciado a, por lo menos, uno de los siguientes criterios: incremento en los requerimientos de oxígeno ( $>50 \%$ del basal), mayor signología obstructiva (estridor en reposo, sibilancias audibles), aumento de fiebre $\geq 39{ }^{\circ} \mathrm{C}$ y/o cambios en el hemograma y la PCR, según la descripción antes mencionada.

Se consideró criterio de alta a: temperatura axilar $<37,5{ }^{\circ} \mathrm{C}$ (al menos 24 horas), buena tolerancia oral (100\% de su requerimiento) y ausencia de hipoxemia al menos 24 horas.

Análisis estadístico. Se empleó el paquete estadístico SPSS para Windows; considerando los promedios expresados como media con su desviación estándar (DE) para las variables de distribución normal continuas y las medianas para aquellas de distribución no normal. Se empleó la prueba $t$ student o Mann-Whitney para establecer diferencias, considerando estadísticamente significativas aquellas con $\mathrm{p}<0,05$.

\section{Resultados}

Epidemiología. Durante el período seleccionado ingresaron al Servicio de Pediatría por alguna condición respiratoria 3.043 niños (77\% bajo 2 años de edad). En 1.585 (52\%) se solicitó IFD para virus respiratorios (según el criterio del médico de sala), resultando 913 $(58 \%)$ de las muestras positivas: VRS 720 (79\%), virus FLU 107 (12\%) y VPIh 64 (7\%). Los VPIh identificados representaron $2 \%$ de las hospitalizaciones por causas respiratorias. La distribución de los serotipos de VPIh 1, 2 y 3 fue: $11(17 \%), 30(47 \%)$ y $23(36 \%)$, respectivamente. Se encontró co-infección respiratoria con VRS en cuatro pacientes. La Figura 1 muestra la distribución mensual de todos los VPIh identificados, según sus respectivos serotipos. Sesenta por ciento de las hospitalizaciones por VPIh ocurrieron entre mayo y julio, siendo esto más evidente durante el año 2003. Cuarenta y cinco por ciento de todas las hospitalizaciones ocurrieron en invierno. La Figura 2 muestra el perfil epidemiológico global de cada serotipo de VPIh identificado, según la estación del año. El serotipo 1 produjo brotes preferentemente en otoño $(64 \%)$, el serotipo 2 en otoño-invierno (70\%) y el serotipo 3 en invierno (65\%), siendo estas diferencias significativas $(\mathrm{p}<0,05)$. El serotipo 3 fue prevalente durante los años 2001 y 2002, mientras que el serotipo 2 resultó ser el VPIh más frecuente durante los años 2003 (40\%) y $2004(81 \%)$.

Manifestaciones clínicas. La edad promedio de los niños hospitalizados fue de 13 meses (rango: 1 mes-12 años) siendo $44 \%<12$ meses (Figura 3) y 40 fueron 
hombres. Se encontró un clara asociación entre la edad del paciente y el serotipo identificado $(p<0,05)$ siendo los serotipos 2 y 3 los más frecuentes en los niños bajo 12 y 24 meses de edad ( 82 y $80 \%$, respectivamente) (Figura 4). Se obtuvieron antecedentes clínicos completos de 52 (82\%) niños, a partir de sus fichas clínicas de hospitalización. En $8(17 \%)$ existió algún grado de desnutrición y 17 (33\%) tenían antecedente de prematurez. Treinta y ocho (73\%) registraban al menos una hospitalización previa por causa respiratoria, $17(33 \%)$ tenían alguna condición crónica, dentro de las que destacaban: enfermedades genéticasmetabólicas (n: 8), bronquiolitis obliterante (n: 6), cardiopatías congénitas (n: 5 , una cianótica), enfermedad neurológica (n: 5) y enfermedad muscular (n: 4). Nueve niños presentaron al menos dos condiciones crónicas simultáneas. Treinta y cinco (67\%) niños tenía antecedentes respiratorios: 26 sibilancias recurrentes y nueve al menos una neumonía. Treinta por ciento de los niños estuvo en contacto con un familiar con síntomas respiratorios previo a la hospitalización.

Los principales motivos de consulta al Servicio de Urgencia (SU) fueron fiebre y dificultad respiratoria (80\%), con síntomas respiratorios de 3,2 días de duración (rango: 0,5-21 días), siendo los más frecuentes: fiebre $(75 \%)$, dificultad respiratoria $(63 \%)$ y tos $(60 \%)$. El examen físico en el SU reveló: fiebre $(81 \%)$, polipnea $(80 \%)$, hipoxemia $(77 \%)$, taquicardia $(76 \%)$, retracción subcostal (58\%), crepitaciones (48\%), sibilancias (46\%) y estridor inspiratorio (27\%). La hospitalización tuvo una duración promedio de 4,8 $\pm 4,5$ días (rango: $1-28$ días) en la población general; mientras que bajo los 6 meses de edad fue de 3,2 $\pm 1,9$ días (rango: 1-7 días), diferencia estadísticamente no significativa.

Los diagnósticos clínicos al egreso fueron: 21 (40\%)

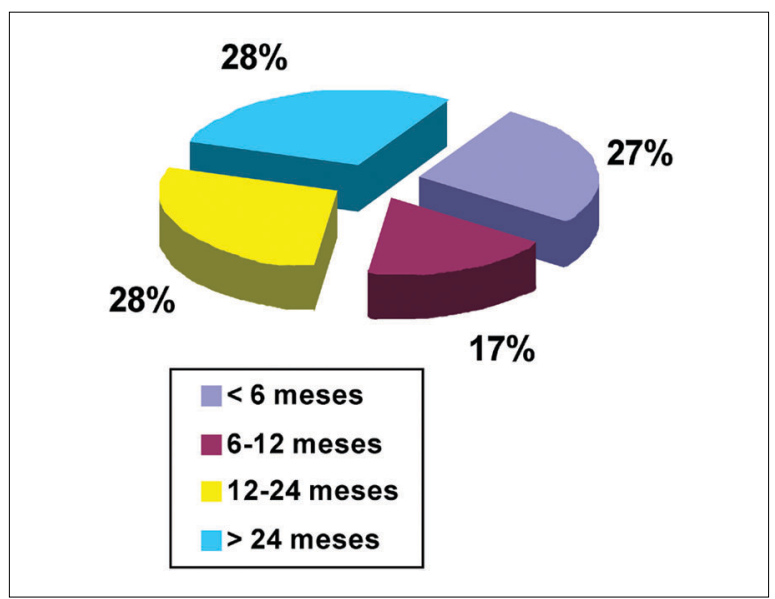

Figura 3. Distribución etaria de 64 niños con infección por VPIh.

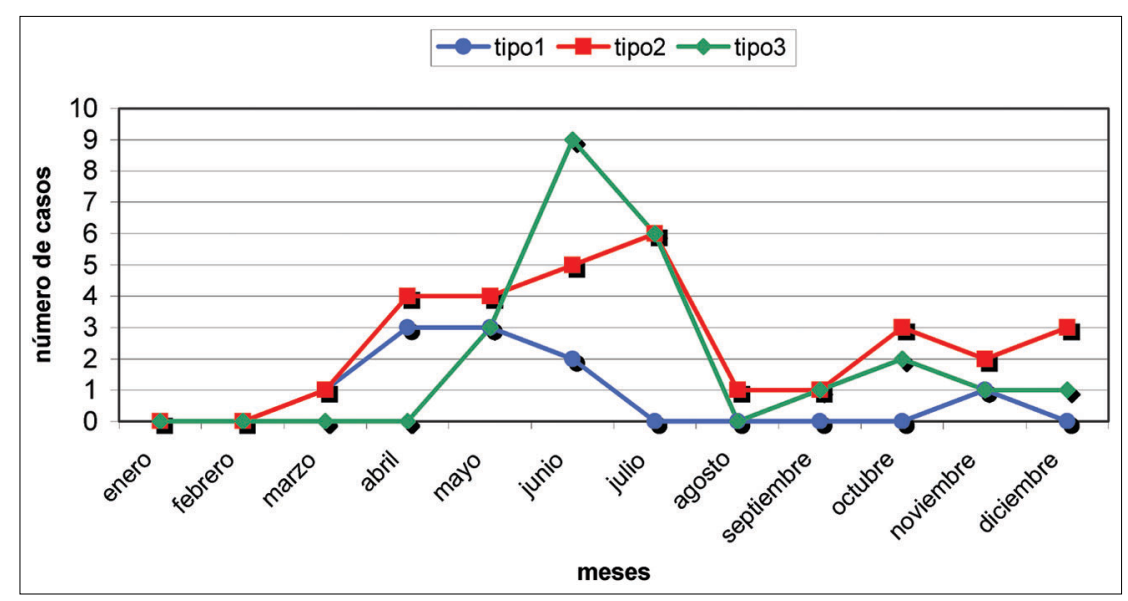

Figura 1. Distribución mensual de la infección por VPIh entre enero 2001 y julio 2004, según serotipos.

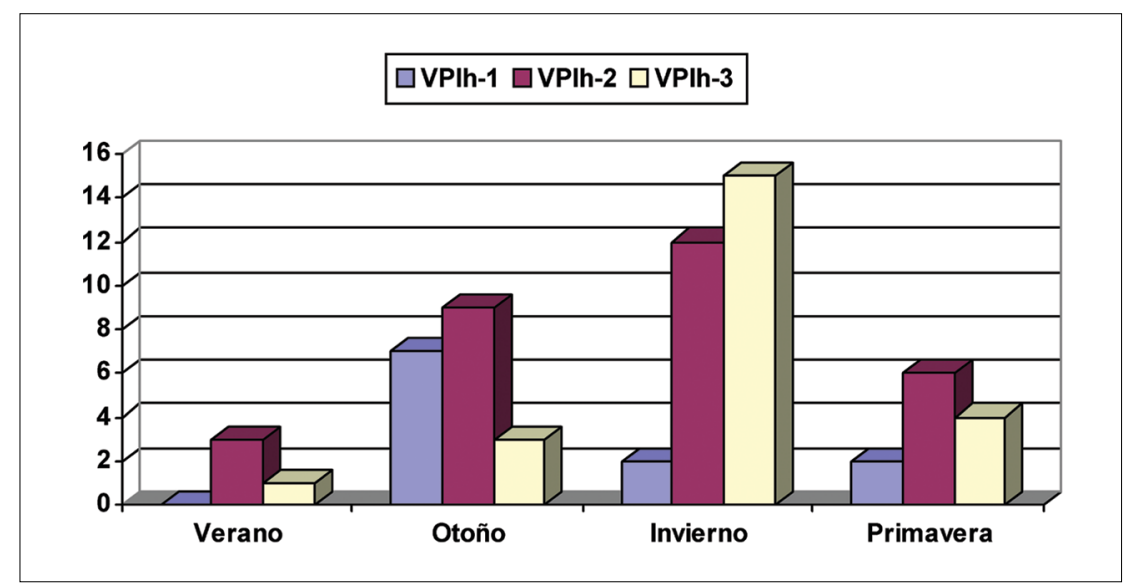

Figura 2. Distribución estacional de la infección por VPIh durante el período enero 2001 a diciembre 2004, según serotipos.

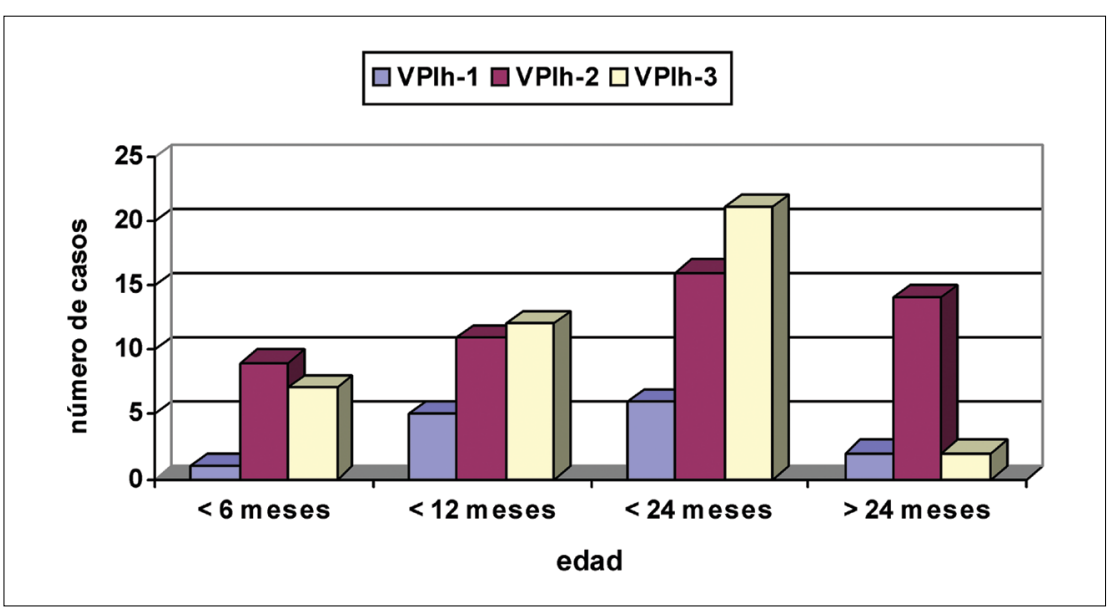

Figura 4. Distribución etaria de 64 niños con infección por VPIh, según serotipos. 
sibilancias asociadas a virus, 16 (30\%) neumonía, nueve laringitis o laringotraqueobronquitis y seis síndrome febril. En 50\% de las neumonías por VPIh se identificó el serotipo 3; por otra parte, $45 \%$ de los VPIh-1 estuvo asociado a neumonía. En $90 \%$ de los niños con sibilancias asociadas a virus se detectó VPIh 2 y 3 mientras que en $83 \%$ de los niños con síndrome febril se identificó VPIh 2. Se encontró VPIh-1 en 44\% de los cuadros de croup. Los niños sin condiciones crónicas de base presentaron, principalmente, croup o sibilancias asociadas a virus (85\%) mientras que los sujetos con condiciones crónicas de base, principalmente neumonía $(80 \%)$, lo que resultó estadísticamente significativo $(\mathrm{p}<0,05)$.

Laboratorio. Se realizaron hemograma y/o PCR en 33 pacientes al momento de la hospitalización, destacando un recuento de leucocitos promedio, al ingreso, de $11.973 \pm 6.250 / \mathrm{mm}^{3}$ (rango 4.900-30.500). Ocho niños presentaron leucocitosis $\left(>15.000 / \mathrm{mm}^{3}\right)$ y no se pesquisó ningún caso de leucocitopenia. La PCR promedio fue 3,9 $\pm 3,4 \mathrm{mg} / \mathrm{L}$ (rango: $1-16$ ), en 10 casos fue $>4 \mathrm{mg} / \mathrm{L}$ (valor normal: $<1 \mathrm{mg} / \mathrm{L}$ ). Se evidenciaron cambios en estos exámenes durante la hospitalización en 25 casos (leucocitosis) asociado a aumento de la PCR $\geq 2$ veces en siete de estos pacientes; en 24 de ellos se consideró que el cuadro clínico correspondía a neumonía probablemente bacteriana.

Tratamiento. Cuarenta niños $(77 \%)$ recibieron oxigenoterapia durante la hospitalización. El aporte de oxígeno fue necesario durante dos días en promedio (rango: 12 horas-14 días). Se administró nebulizaciones con adrenalina en $39(76 \%)$ pacientes. Veinticuatro niños recibieron antimicrobianos durante la hospitalización por deterioro clínico y sospecha de neumonía bacteriana (14), leucocitosis $\geq 17.500 / \mathrm{mm}^{3}$ (4), fiebre mayor de tres días (4) y aumento de los requerimientos de oxígeno a $\mathrm{FiO}_{2}>50 \%$ (2). Se observaron complicaciones en nueve pacientes, principalmente, asociadas al aumento de síntomas obstructivos (6). Se registraron tres ingresos a UCI pediátrica por incremento de los requerimientos de oxígeno y deterioro del estado general, con necesidad de ventilación mecánica invasora en uno, máscara con BiPAP en el segundo y flujo alto de oxígeno $\left(\mathrm{FiO}_{2}>80 \%\right)$ en el tercero. No hubo pacientes inmunocomprometidos ni se registraron muertes en esta serie.

\section{Discusión}

A pesar que VPIh es considerado un agente infeccioso frecuente en la edad pediátrica, escasea la información publicada en torno a los aspectos clínicos o epidemiológicos específicos que caractericen a estos virus en nuestro medio o Sudamérica. A pesar de ser éste un estudio retrospectivo y aunque sólo $52 \%$ de los pacientes hospitalizados en el Servicio de Pediatría del HCPUC tenían algún estudio etiológico viral, esta serie representa el primer reporte clínico y epidemiológico publicado en Chile que revela el perfil clínico-epidemiológico específico de los niños hospitalizados por infección con VPIh.

Durante el período de estudio, VPIh representó la tercera etiología responsable de hospitalización por cuadro respiratorio con diagnóstico virológico, de manera similar a otros estudios nacionales ${ }^{17,19}$. VPIh representó la décima parte de las hospitalizaciones producidas por VRS en el mismo período (información no presentada); sin embargo, la descripción del espectro de manifestaciones respiratorias producidas por VPIh es importante, dado que constituyen agentes que circulan todos los años en épocas frías en Chi$1 \mathrm{e}^{17,19,20}$. VPIh apareció desde la semana epidemiológica número 10 , extendiéndose hasta la semana 50, alcanzando un nivel máximo entre las semanas 20 y 30 , período en el cual se concentró el $52 \%$ de los casos pediátricos hospitalizados. Mientras los serotipos 1 y 2 aparecieron alrededor de la semana 10, el serotipo 3 hizo su aparición alrededor de la semana 20, coincidiendo con el mayor número de hospitalizaciones. Se ha descrito que VPIh serotipo 3 produce brotes epidémicos en invierno y que afecta en forma grave a pacientes inmunocomprometidos ${ }^{22,23}$.

En esta serie, la mayoría de niños correspondió a pacientes bajo 24 meses de edad, en los que predominó VPIh del serotipo 3, en forma similar a lo reportado por algunos autores ${ }^{2,17,22}$ y diferente de otros ${ }^{1,5}$. El grupo de niños sobre dos años de edad concentró el $77 \%$ de los VPIh serotipo 2. La distribución de edad de esta serie fue similar a lo publicado previamente ${ }^{22}$. Al menos $50 \%$ de todos los niños se infectan el primer año de vida con el VPIh serotipo 3, mientras que entre los doce meses y cuatro años los VPIh 1 y 2 están asociados, frecuentemente, con traqueobronquitis o faringitis ${ }^{2}$.

Nuestros hallazgos confirman que la infección por VPIh puede causar síndromes clínicos similares a los producidos por otros virus (VRS, FLU, ADV) sin existir formas características o patognomónicas de infección $^{18,21}$. Si bien VRS es el virus más frecuentemente identificado en diversas publicaciones nacionales o extranjeras, muchos de los síntomas respiratorios que se le describen son inespecíficos. En esta serie, el síntoma más frecuente fue la fiebre; en general, la gravedad de las manifestaciones depende del tipo de virus y de la inmunidad del huésped ${ }^{13,24}$. Esta serie no incluyó pacientes inmunocomprometidos. 
Cincuenta por ciento de los pacientes infectados por VPIh 2 desarrollaron un compromiso bronquiolar presentando sibilancias e hipoxemia ${ }^{9}$. Hoy en día, se reconoce una asociación entre la infección grave por VRS y el desarrollo de sibilancias y, eventualmente, asma en el niño pequeño; existen teorías que postulan un cambio en el desarrollo inmune mediado por linfocitos $\mathrm{Th} 2^{25}$. Aunque estas teorías no son exclusivamente aplicables a la infección por VRS, es probable que mecanismos inmunes similares participen en la génesis del asma en relación con virus FLU o VPIh.

Existe una estrecha relación entre serotipo, síndrome clínico, edad del niño y la estación del año. El croup viral (laringotraquebronquitis) puede representar hasta $25 \%$ de las infecciones respiratorias bajas en los niños bajo cinco años de edad ${ }^{26}$. El agente responsable puede ser identificado usualmente en $50 \%$ de los casos. Virus parainfluenza humano es responsable de hasta $74 \%$ de ellos, predominando el serotipo $1^{11,18,26,27}$.

La infección por VPIh en adultos, es usualmente asintomática o autolimitada al tracto respiratorio alto. Al menos $30 \%$ de los pacientes con trasplante de precursores hematopoyéticos y $18 \%$ de los adultos de la comunidad desarrollan infecciones por virus respiratorios en algún momento ${ }^{7}$, siendo VPIh del serotipo 3 , probablemente, el más virulento.

Existe una tendencia estacional de las infecciones por VPIh durante todos los años, lo que ha sido corroborado en nuestro medio ${ }^{18}$. En años en que no hay una actividad epidémica del VPIh serotipo 1, el serotipo 2 se hace muy importante ${ }^{28}$.

El serotipo 3 puede causar formas graves de croup en adultos ${ }^{29}$. Si bien existe evidencia que sugiere que el croup secundario a virus FLU es más grave que el producido por $\mathrm{VPIh}^{7,28,29}$, algunos autores han comunicado que la tasa de hospitalización por VPIh puede ser hasta dos veces la tasa de hospitalización por virus FLU en el mismo grupo de edad ${ }^{4}$. En esta serie, el serotipo 1 fue el principal responsable de los cuadros de croup seguido por el serotipo 3. Si bien la mayoría de cuadros de croup son de manejo ambulatorio, aquellos niños con mayor compromiso del árbol respiratorio (tráquea, bronquios), asociado a dificultad respiratoria, requirieron hospitalización, identificándose sólo en $44 \%$ un VPIh.

La incidencia de bronquiolitis durante el primer año de la vida llega hasta $80 \%$, para desaparecer dramáticamente en la edad escolar. Hasta $30 \%$ de las infecciones respiratorias bajas en niños pueden ser bronquiolitis, pero este porcentaje es evidentemente mayor durante el primer año de vida ${ }^{24}$. La tasa de identificación viral en estos cuadros puede ser tan alta como $83 \%{ }^{27}$. Los cuatro tipos de VPIh pueden producir bronquiolitis, siendo los más frecuentes el serotipo 1 y 3; cada uno de ellos representa 10 a $15 \%$ de los casos de bronquiolitis que no requieren internación. Sin embargo, en los niños hospitalizados, el serotipo 3 es más frecuente que el serotipo 1 (tres o cuatro veces más) ${ }^{7}$, hallazgo que coincide con nuestra experiencia.

Hasta $40 \%$ de las infecciones respiratorias bajas en niños hospitalizados corresponden a neumonías ${ }^{27}$. En niños, las neumonías pueden representar hasta $80 \%$ de los motivos de hospitalización ${ }^{30}$. Los virus respiratorios son responsables de 50 a $90 \%$ de estos cuadros; especialmente durante el primer año, disminuyendo lentamente hasta la edad de cinco años ${ }^{7,28,30}$. Menos de $10 \%$ de la neumonías adquiridas en la comunidad por pacientes pediátricos (con algún agente identificado) corresponden a VPIh (serotipos 1 y 3), pero en los niños hospitalizados el serotipo 3 (al igual que en bronquiolitis) puede representar un porcentaje mucho mayor. En esta serie, el diagnóstico clínico más frecuente al momento del ingreso correspondió a neumonía, teniendo $69 \%$ más de un año de edad. El serotipo 3 fue el principal VPIh responsable; en cambio, en los niños pequeños ( $<6$ meses) más de $50 \%$ desarrolló episodios de sibilancias durante su estadía hospitalaria (bronquiolitis, bronquitis aguda, asma). En general, VPIh produce infección, aún en presencia de anticuerpos maternos, pudiendo causar re-infecciones durante los primeros cinco años de la vida. Esto sugiere que la vacuna ideal frente a los VPIh debe brindar una protección de mayor duración que la infección natural $^{31}$.

Surgidas las normas de aislamiento viral propuestas por la OMS en 1981, se ha puesto especial atención en determinar los agentes responsables de infecciones respiratorias bajas, especialmente en pacientes hospitalizados ${ }^{18}$. Por ello, la determinación rápida, permite conductas de aislamiento y disminución de infecciones cruzadas intrahospitalarias, hecho relevante en el caso del ADV. La Academia Americana de Pediatría $^{32}$ publicó el rol del diagnóstico etiológico viral en condiciones respiratorias específicas, estableciendo que, si bien el diagnóstico de bronquiolitis es clínico, el uso rutinario de exámenes auxiliares o pruebas diagnósticas (incluida la radiografía) no está recomendado. Es sabido que la identificación de VRS en bronquiolitis grave se asocia con el desarrollo de sibilancias recurrentes y asma; de manera curiosa, esto no ha podido ser demostrado con VPIh.

En conclusión, esta serie mostró que las infecciones por VPIh que requieren hospitalización afectan, preferentemente, a niños pequeños y se manifiestan como sibilancias asociadas a virus, neumonía o croup, muchas veces indistinguibles de las producidas por otros virus respiratorios, lo que plantea la necesidad de un diagnóstico etiológico precoz ${ }^{32}$. En los casos de 
neumonía, predominó el serotipo 3 y en el caso de las sibilancias asociadas a virus, el tipo 2. La infección por VPIh en niños puede ser responsable de cuadros respiratorios con complicaciones y deterioro clínico, por lo que su reconocimiento precoz debe alertar al pediatra, especialmente, en período de brotes de infecciones respiratorias. Nuestros resultados deben ser considerados para futuras temporadas de invierno en el medio.

Agradecimientos. A la señora Teresa Azócar por su cuidadoso trabajo en el Laboratorio de Virología del Centro de Investigaciones Médicas de la Pontificia Universidad Católica de Chile.

\section{Resumen}

Los virus parainfluenza del ser humano (VPIh) son patógenos importantes de enfermedad respiratoria en niños; pese a ello, existe escasa información publicada en Sudamérica dirigida a caracterizar esta infección. Objetivo: Describir las manifestaciones clínicas y epide- miológicas específicas de los VPIh en niños hospitalizados. Pacientes y Métodos: Se revisaron todas las hospitalizaciones respiratorias (HR) efectuadas en el Hospital de la Pontificia Universidad Católica, Santiago, Chile, durante el período 2001-2004 y sus respectivos estudios virales obtenidos de secreciones nasofaríngeas en aquellos con sospecha de infección viral. Resultados: Se identificaron $3.043 \mathrm{HR}$ siendo 64 (2,1\%) VPIh+. La edad promedio fue 13 meses (rango: $1 \mathrm{~m}-12$ a) siendo $77 \%$ de edad inferior a dos años. VPIh-2 fue el serotipo prevalente $(47 \%)$, observándose una tendencia estacional para los serotipos 2 y 3 . Las presentaciones más frecuentes fueron sibilancias asociadas a virus $(40 \%)$ y neumonía $(30 \%)$. Todas las bronquiolitis se presentaron asociadas a VPIh serotipos 2 y 3 . Sólo $17 \%$ de los hospitalizados por VPIh+ (44\% VPIh-1) desarrollaron laringitis. Conclusión: Virus parainfluenza humano puede ser responsable de HR en niños, mostrando una tendencia estacional VPIh-2 y el serotipo 3. Aunque son poco frecuentes como causa de HR, confirmamos su participación como etiología específica de laringitis, bronquiolitis y neumonía, especialmente en niños pequeños.

\section{Referencias}

1.- Glezen W P, Greenberg S B, Atmar R L, Piedra P A, Couch R B. Impact of respiratory virus infections on persons with chronic underlying conditions. JAMA 2000; 283: 499-505.

2.- Redd G, Jewett P H, Thompson J, Tollefson S, Wright P F. Epidemiology and clinical impact of parainfluenza virus infections in otherwise healthy infants and young children $<5$ years old. J Infec Dis 1997; 175: 807-13.

3.- Kim M R, Lee H R, Lee G M. Epidemiology of acute viral respiratory tract infections in Korean children. J Infect 2000; 41: 152-8.

4.- Iwane M K, Edwards K M, Szilagyi P G, Walker F J, Griffin M R, Weinberg G A, et al. New Vaccine Surveillance Network. Population-based surveillance for hospitalizations associated with respiratory syncytial virus, influenza virus, and parainfluenza viruses among young children. Pediatrics 2004; 113: 1758-64.

5.- Knott A, Long C, Hall C. Parainfluenza virus infections in pediatric outpatients: seasonal patters and clinical characteristics. Pediatr Infec Dis J 1994; 13: 269-73.

6.- Whimbey E, Englund J A, Couch R B. Community respiratory virus infections in immunocompromised patients with cancer. Am J Med 1997; 102: 10-8.
7.- Henrickson K J. Parainfluenza viruses. Clin Microbiol Rev 2003; 16: 242-64.

8.- Storey D G, Dimock K, Kang C Y. Structural characterization of virion proteins and genomic RNA of human parainfluenza virus 3. J Virol 1984; 52: 761-6.

9.- Slavin K A, Passaro D J, Hacker J K, Hendry R M, Kohl S. Parainfluenza virus type 4: case report and review of the literature. Pediatr Infect Dis J 2000; 19: 893-6.

10.- Glezen W P, Frank A L, Taber L H, Kasel J A. Parainfluenza virus type 3: seasonality and risk of infection and reinfection in young children. J Infect Dis 1984; 150: 851-7.

11.- Henrickson K J, Kuhn S M, Savatski L L. Epidemiology and cost of infection with human parainfluenza virus types 1 and 2 in young children. Clin Infect Dis 1994; 18: 770-9.

12.- Carballal G, Videla C M, Espinosa M A, Savy V, Uez O, Sequeira M D, et al. Multicentered study of viral acute lower respiratory infections in children from four cities of Argentina, 1993-1994. J Med Virol 2001; 64: 167-74.

13.- Tsai H P, Kuo P H, Liu C C, Wang J R. Respiratory viral infections among pediatric inpatients and outpatients in Taiwan from 1997 to 1999. J Clin Microbiol 2001; 39: 111-8.
14.- Escobar C A M, Martínez R F, Ceruti D E, Díaz C A, Vicente S M, Farías T P, et al. Etiología de las infecciones agudas del tracto respiratorio bajo (IRAB) en lactantes hospitalizados: estudios virológicos. Rev Chil Pediatr 1988; 59: 349-53.

15.- Vicente S M, Wu H E, Carrasco S L, Acevedo R C, Ramírez F R, Peña D A M, et al. Participación viral en las infecciones respiratorias agudas bajas del lactante. Rev Chil Pediatr 1988; 59: 353-7.

16.- Papic G Z, Rodríguez O L, Larrañaga L C, Avendaño C L F. Virus respiratorios en lactantes con infecciones respiratorias alias y bajas. Rev Chil Pediatr 1992; 63: 256-61.

17.- Portillo C M, Cruz J. Implementación del método rápido de diagnóstico de virus por inmunofluorescencia en niños hospitalizados por infecciones respiratorias agudas. Rev Chil Pediatr 2000; 71: 72-7.

18.- Iñiguez F, Vega-Briceño L E, Pulgar D, Díaz P C, Sánchez D I. Laringotraqueobronquitis en niños hospitalizados: Características clínicas. Rev Chil Pediatr 2005; 76 : 357-62.

19.- Lagos R, Avendaño L, Levine M. Vigilancia sistemática de virus influenza, respiratorio sincicial, parainfluenza y adenovirus, en niños ambulatorios con infecciones respiratorias agudas. Rev Méd Chile 1999; 127: 1063-72.

20.- Avendaño C L F, Céspedes L A, Stecher G X, 
Palomino M M A. Influencia de virus respiratorios, frío y contaminación aérea en la infección respiratoria aguda baja del lactante. Rev Méd Chile 1999; 127: 1073-8.

21.- Vega-Briceño L, Potin M, Bertrand P, Sánchez I. Clinical features of respiratory infections due to influenza virus in hospitalized children. Rev Méd Chile 2005; 133: 911-8.

22.- Yang T Y, Lu C Y, Kao C L, Chen R T. Clinical manifestations of parainfluenza infection in children. J Microbiol Immunol Infect 2003; 36: 270-4.

23.- Counihan M E, Shay D K, Holman R C, Lowther S A, Anderson L J. Human parainfluenza virus-associated hospitalizations among children less than five years of age in the United States. Pediatr Infect Dis J 2001; 20: 646-53.
24.- Shay D K, Holman R C, Newman R D, Liu L L, Stout J W, Anderson L J. Bronchiolitis-associated hospitalizations among US children, 1980-1996. JAMA 1999; 282: 1440-6.

25.- Welliver R C. Review of epidemiology and clinical risk factors for severe respiratory syncytial virus (RSV) infection. J Pediatr 2003; 143 (5 Suppl): S112-7.

26.- Denny F W, Murphy T F, Clyde W A Jr, Collier A M, Henderson F W. Croup: an 11year study in a pediatric practice. Pediatrics 1983; 71: 871-6.

27.- Denny F W, Clyde W A Jr. Acute lower respiratory tract infections in nonhospitalized children. J Pediatr 1986; 108 (5 Pt 1): 635-46.

28.- Marx A, Torok T J, Holman R C, Clarke M J, Anderson L J. Pediatric hospitalizations for croup (laryngotracheobronchitis): biennial increases associated with human parainfluenza virus 1 epidemics. J Infect Dis 1997; 176: 1423-7.

29.- Woo P C, Young K, Tsang K W, Ooi C G, Peiris M, Yuen K. Adult croup: a rare but more severe condition. Respiration 2000; 67: 684-8.

30.- Chien J W, Johnson J L. Viral pneumonias. Epidemic respiratory viruses. Postgrad Med 2000; 107: 41-2.

31.- Ewasyshyn M, Cates G, Jackson G, Scollard N, Symington A, Klein M. Prospects for a parainfluenza virus vaccine. Pediatr Pulmonol Suppl 1997; 16: 280-1.

32.- American Academy of Pediatrics Subcommittee on Diagnosis and Management of Bronchiolitis. Diagnosis and management of bronchiolitis. Pediatrics 2006; 118: 1774-93. 